\title{
FILOSOFIA
}

\section{Estética y Existencialismo}

\section{Filosófico}

Las siguientes reflexiones tienen por objeto indagar acerca de las posibilidades del existencialismo estético, frente a las corrientes pragmatista (1), fenomenológica y axiológica estéticas, todo ello, desde un estricto punto de vista filosótico.

Con el señalamiento de los aspectos que a continuación se revisa, sería equivocado entender que en las corrientes contrapuestas al existencialismo, dejen de brirdarse fecundos aportes para la aclaración de! fenómeno estético pués, lo único que se pretende es mostrar, mediante una discriminación critica, los asuntos en los cuales el existencialismo -en dispersas y huidizas aseveraciones $\mathrm{por}$ lo general difíciles de descubrir - proporciona una solución filosófica más adecuada de la realidad estética.

Las observaciones que posteriormente se anotan, sobre el pragmatismo y sobre las direcciones fenomenológica yaxiológica, subrayan el carácter fundamental de las mencionadas corrientes y no, en especial, las numerosas apreciaciones personales, emitidas por los representantes de cada una.

(*) Ponencia presentada al Tercer Consreso Interamericano de Filosolia, colebrado en México del 11 al 2.0 de Enero de 1950.

(1) Denominase aqui pragmatismo estéticn, a las teorias estéticas que consideran este fenómeno como un suceso que slecta posíliva o negativamente al sujeto, produciendo placer o displacer, ya de carácter orgánico, sexual, etc. (biologismo): ya de carácter sentimental (psicologismoi estados bio-psíquicos que le son útiles al sujeto en el desarrollo de su vida. 
Se advierte también, que dentro de los ajustados límites permitidos al presente trabajo, eúlo se expondrán brevemente las nuevas perspectivas que ofrece el existencialismo estético, reservando un estudio analitico para otra oportunidad.

El actual estudio aborda los problemas relacionados con:

1.-Sentido de la experiencia estética.

2.-Estratos en el vivir estético.

3.-Comprensión unitaria de lo estético a través de lo extraestético Y viceversa.

4.- Genuino significado de la creación artística.

5.-Superación del subjetivis:no y objetivismo estéticos.

La actitud existencialista, descubre un rasgo peculiarísimo e inédito del "experimentar estético", al considerarlo como fundamento en la constitución del ser de los objetos que conforman el mundo y el plan de dicho mundo en función de la existencia humana y, como el clima apropiado para la elaboración individual de la esencia del hombre, valiéndose del conjunto de posibilidades que integran su existencia.

La experiencia estéfica, pues, viene aver el resorte humano ineludible del ser de lo dado con carácter de "mundo" y de la esencia lograda en el existir humano.

Caso significativo, lo hallamos en Martín Heidegger cuando investiga la "Esencia de la Poesía" (2).

La anterior apreciación, a través de las investigaciones actuales fenomenológicas y axiológicas sobre el fenómeno estético, júzgase forastera, porque trastruesa la fisonomía del aludido fenómeno, otorgándole un cariz metafísico que rebasa la propia interpretación de su esencia.

Pero aquel!o, si es que pudiera ser objetable en las diversas con. cepciones metafísicas (Flatón, Shopenhauer, el idealismo alemán, elc.), donde el vivir estético es únicamente "instrumento", no es congruente al existencialismo, que admite la calidad estética consubstancial a la esencia humana y su mundo, siendo imposible por lo tanto desligar de ella la raigambre metafísica.

(2) v. M. Heidegger, "Hoelderling y la Escuela de la Poesia", cap. II, III, y IV. 
La importancia del punto de vista esbozado, alcanza mayor nitidez cuando se le compara con los principios que rigen el pragmatismo, la fenomenologia y ià axiología al respecto.

El biologismo y psicologismo estéticos, tan difundidos, propugnan respectivamente sintetizando su cometido primero, que el sentido de la expeliencia estetica no es otra cosa que un comercio, un intercambio adecuado entre los Esimuios y el organismo que responde hedónicamente en ia creación y en la contemplación y segundo, que la citada experiencia se traduce en variadas reacciones sentimentales de placer o displacer.

Posiciones pragmátiças, que en lugar de aclarar el problema, io encubren proponiendo la superficial explicación del agrado o desagrado pasajeros, de la experiencia sentida, de la ilusión manifiesta, del entusiasmo aparente, etc., haciendo flotar el vivir estético en un caos insubstancial y explicándolo con el insólito argumento del "misterio" que lo sustenta.

La dirección fenomenolćqica, mantiene un hermetismo ante lo que no sea estético, bajo el persistente argumento de la intuición de su esencia, por un anclaje en el descubriniento de las leyes que rigen la conciencia estética, sacrificando la estructura psíquica empírica. Lamentable error, ni clausura de do estético frente a lo extraestético, ni sacrificio de lo psicoiógico lenpírico, fues, si bientaleanza la fenomenología ciertas determinaciones de li concienchả estéticangura y de su contenido, deja un vacio inconcebible respecto a su motivación germinal y aunque se ampare, en última circunstancia, en el telos valorativo - del cual tampoco se hace problemática o explicacićn de su génesis, por considerarla no estéticá- la fenomenología flaquea a la luz de toda auténtica determinación filosófico-estética, su presión científica la ahoga.

La corriente axiológica en lo concerniente al tema que se revisa, ya sea normativa formal donde se supedita lo estético a lo lógico y a la valoración teórica o ya sea emocional, donde se le interpreta como la aprehensión de una forma expresiva valiosa, exige a pesar del reconocimiento de fines específicos otra explicación, que plantea muy acertadamente Odebrecht (3), al proponer una respuesta ontológica eztética inicial.

(3) v. R. Odebreclit، "La Estŕtica Contemrorínea". 
Por tanto, el existencialismo estótico, proporciona un punto de parlida $y$ ubicación de la experiencía estética ajuslado a la determinación humana y abre el camino para investigarla desde alli, en sus núltiples matices.

Quien meditase sobre algunas aseveraciones existencialistas referentes a: el hombre en el mundo; la relacićn con el otro; la angustia; la libertad y, lav contemplara desde la realidad estética, por las observaciones breves pero fecundas que en relación a tales cuestiones hace $O$. Becker, J. P. Sartre y M. Heidegger, podría seguramente obtener la conclusión de que el existercialisino. propone la dación de esiratos estéticos según la situación jerárquica de la existencia humana con su mundo. Modalidad que expresa por qué entre el manojo de posibilidades de la existencia y el conjunio de condiciones que ofrece la circunstancia, haya una tensión afe-tiva parpadeante --momento estético- que labora en la visión acorde o ho de la situación humana con su circuns. tancia y que transparenta todo lo dado, en relación con la jerarquía alcanzada por la existencia en su mundo.

Desde esta arista, se Comprende a pertección, las íluctuaciones del mismo fenómeno estélice, Hàlbellezal lipon ejemglov en los distintos sujetos $\mathrm{y}$ agregados sociales. Ni el objeto permanece inmutable $\mathrm{y}$ se hace distinto por la calidad emotiva y momentánea del sujeto, ni a su vez el sujeto en cada caso foria a su manera el objeto estético. Subsiste una proyección conjunta de la situación afectiva que define el mundo estético y que justifica tantc, la apreciación o creación primaria decadente, como la intermedia o la superior, sin que esto impida una prospectividad existencial a la perfectibilidad estética.

Cabe en consecuencia, puntualizar un estado emotivo de tensión, que determinaría la concreción sui generis del fenómeno estético, para cada estrato existencial; sin que esto suponga subjetivización o vaya en desmedro de las características que ostenta el hecho o ejemplar artístico.

No sucede lo mismo en el pragmatismo. La orientación biologista estética, sugiere como úmica realidad la configurada por la excitación orgánica (físiológica, sexual). Según se adopten variantes en la concepción biológica (biologismo estético extremo o moderado), será la 
interpretación de la excitación estética, pero siempre delimitada por lo orgánico. La posición psicológica no admite asimismo, en el vivir estélico, otra estructura que la impuesta por la afectividad. También, según sean las clases de teorias psicológicas estéticas, será la explicación del comportamiento de la afectividad.

El vivir estético, en ambas teorías, no aspira a la superación de los limiles orgánico-sentimentales, está encerrado en ellos, actúa con exclusividad en el mismo estrato.

En lá fenomenología, sólo se admite un vivir estético: el esencial; lo quie no posea estas características, es pseudo estético. Los fenómenos que se acerquen o alejen del canon prefijado, serán más o menos estéticos.

Aunque ea forma diferente a la corriente pragmática, la fenomenología encapsula cualquiera posición dentro de una pauta, que admite tan sólo variantes del modelo eidético y no concede a cada situación humana, su independiente peso estético, y su libre acceso al estrato superior.

Para la axiología estética, ocurre un vivir afeclivamente la forma valorativa impuesta, vivir que fluctúa, debido a los distintos grados de sensibilidad de los suietos, pudiendo originarse tanto, la máxima visión valorativa estélica, cuanto, la ceguera (casi nula sensibilidad en la captación).

Los diverses estrabs deta sensibilidad, tho sons sino matices de un mismo fenóneno, nūncag posiciones don validez substantiva, como aconlece en el existencialismo.

Muchas polémicas ha suscitado el estudio del fenómeno estético $y$ de su unidad con los fenómenos extraestéticos. Corrientemente se ha sostenido, ya la tendencio que mutilà lo extraestético para comprender lo estético; ya la concepción que al fijar la mirada en lo extraestético dado, cuando se vive lo estético, llega a desnaturalizarlo.

Si se contempla el enfoque que el existencialismo procura en este sentido, saile a luz su posición original. Cuando el hombre como ser existente en un mundo, se va revelando en su esencia y alcanza, por un volverse a si mismo, la intuición de la nada y por la angustia sien- 
te su existencia, como un trascenter "allende el ente en total" (4). ha tenido constantemente que desplazarse en continua tensión afectiva momento estético- consumiendo $y$ elaborando en su ser para si y para el otro, todas sus posibilidades humanas en el "pathos estético", si podría asi denominársele. Nunca pues, el hombre tiene convicción de lo estético aislado como efusión contemplativa simpática o desfavorable, sino, que dicho fenómeno va impregnado de los elementos humanos extraestéticos.

Se obtione con el existencialismo. la comprensión unitaria de lo estético a través de lo extrzestético y también, de lo extraestético mndiante la calidad estética, no se vive lo uno sin lo otro. Parafraseancio a Kant, se nuede decir que desde el punto de vista de la existencia humana, lo extraestético sin lo estético es ciego, y lo estótico sin lo cxtr estético vacío, sin que ninguno de los componentes pierda su ficonomía característica.

Pero ha de entenderse bien, que en el existencialismo estético, no se acopta una posición idéntica a la de Dilthey en su conceprión del creador, del artista frente a la realidad histórica. En el caso de Dithey. el hecho estético se constituye por la unidad que olcanza el conienito histórico de un ejemplar artístico, debido a la afinidad de sus elementos. $E l$ genio logra la mencionada unidad (5).

Dithey, ensambla en la vivencia creadora fos elementos estéticos $\mathrm{v}$ extraestéticos, másolos prinueros lsirvendermoldes efusivos transporentes del momento histórico, en cambio para Heidegger, poniendo de ejemplo sus reflexiones sobre la "Esencia de la Poesía" y extendiendo ese criterio a la creación artística, transida por su puesto, de color estético, la estructura de tensión "existencia-mundo" denominada anteriormente "pathos estético", se da en conjunto con lo estético reflejando siempre el ser del hombre y sirviendo de fundamento del devenir histórico.

No acontece lo expuesto en la corriente pragmática, donde se traduce una aparente y deleznable convicción a! abordar el hecho estético confundiéndolo con factores a todas luces extraestéticos. En virtud de la confusión anotada, tampoco se toma en consideración, el problema importantísimo de la correlación estético-extraestética.

(4) v. Heidegger, "¿Qué es Melafísica?", cap. 3.

(5) v. W. Dilthey, "Vida y Poesía" y "Psicología y Teoría del Conocimiento". 
Desde la perspectiva fenomenológica, se distingue con exactitud el carácter de lo estético y se le diferencia notoriamente de lo extraestético. Si bien, ello presupone un pulcro avance en el deslinde de compos, obstaculiza gue se distinga como ineludible el problema de la esencia de lo estético, su dación conjunta con lo extraestético y su unitaria gestión.

La axiolocria, en sus investigaciones más sutiles acerca del valor estélico, encara el problema presente y le imprime una cariz que secún parece no llega al nivel del existencialismo, pues, le falta el peso de la consideración ontológica. En la axiología, se anota la correlación entre los valores extraestéticos que conforman el ejemplar artístico, en función del valor estético y, pasa inadvertida la unidad de los factores materiales, psíquicos $y$ espirituales.

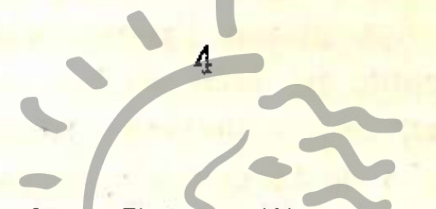

Con mucho acierto indica Geiger (6), que las teorías sobre la creación artística, liberadas de una fraseología inútil, y procurando evaluar la naturaleza de lo estético desde allí. conducirían a insospechados pro. gresos en la investigación estética.

Asoman reflexiones en el existencialismo que transparentan una reculiar y nueva visić de la creacich artistica. Ni la intencionalidad

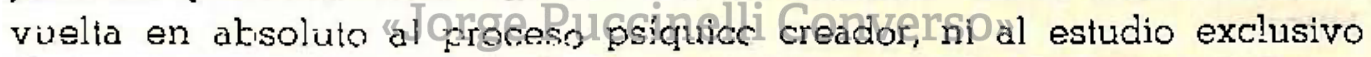
de la obra. Toda creación artística está impregnada de un principio vital afectivo estético y por él adquiere significado. La existencia humana en general, se desenvuelve con potencialidades creddoras que obtienen mayor vivacidad en el geniø. Sin embargo, alimenta ese don, la presión afectiva estética cuyos resortes humanos son la angustia y la libertad. El punto culminante, en consezuencia, para ahondar en ¿qué es el hombre?, ¿qué la existencia?, aflora en la creación artística donde el clima estético brilla romo traductor expresivo de la individualidad. La creación así se yergue como la acción incomparable que permite avisorar con nitidez el meollo de lo estético y su finalidad en la existencia humana. Es el instante metafísico por excelencia, para introducirse en la realidad estética humana.

(6) v. M. Geiger, "Estétira". 
A primera vista, fuera dable argumentar que la actitud descrita, la encontramos en antiguas tendencias metafísico-estéticas idealistas, empero, en ellas otra es la mistón del fenómeno revisado, hecho estético y hombre ejercen el papel de intermediarios del ideal melafísico preconcebido y son su eco ontológico.

Comentar en esta oportunidad, acerca de la opinión que la creación artística le merece al biologismo, es ingresar en una descriptiva de la actividad del organismo, que no nos incumbe ahora.

Los estudios psicológicos de la creación artística, son más valiosos pero también, muy poco comentan, de otra cosa que no sea la exposición de los factores psíquicos que intervienen en el proceso creador y de las características psicológicas del genio.

Fenomenológicamente se ha verificado un análisis importante de la creación, destacando sus etapas tipicas: visión, elaboración y objetivación, poniendo el acento no sólo en los factores psíquicos, sino en los demás faciores subjetivos y objetivos. Se emiten argumentos interesantes sobre la generación de lo estético, sobre todo en las dos últimas ełapas (elaboración y objetivación), pero lo que se persigue primordialmente, es demostrar las cualidades y límites de la vivencia creadora y no la esiructura del telos estético que aflora en ella y desde allí vislumbrar su cometido, naturaleza y alcances. Hay una similitud con la solución bosquejada en la axiología estẻtica, pues los análisis fenomenológicos, precisamente demuestran el cómo de la creación del valor estético.

Por eso, aparte del existencialismo donde la creación artística es la genuina senda para abordar la esencia de lo estético, las otras teorías consignan resultados parciales y analizan la creación por la creación misma, escapándoseles o rozando circunstancialmente el problema del fenómeno estético.

\section{5}

Es una consecuencia inevitable de lo anterior, resaltar que el existencialismo no admite el subjetivismo y el objetivismo estéticos. Lo supera ampliamente $y$ aire una ruta que en materia estética parecía infranqueable.

Los argumentos biológicos y psicológicos son en su mayoría subjetivistas y de menor escala, objetivistas. Otros, aspiran a una posi- 
ción intermedia pero sin rebasar la encrucijada sujeto-objeto, que a menucio les crea complicadas soluciones.

Los estudios ínomenológicos, encuentran en la vivencia valorativa estética, la partizipación del sujeto y el objeto y el plus que las engloba en el vivir es ztico, es decir el valor. Con esto parece superarse el subjetivis:no y obietivismo estéticos; empero, averiguando por el valor, se cae en la objetividad o subjetividad del mismo. Y la dialéctica y polémica sique interminable.

\section{$* * *$}

Conviene remarcar que los cinco puntos delineados en sus rasgos generales, revelan intenciones existencialistas estéticas que pueden utilizarse como derroteros para las futuras investigaciones. Con lo cual, no se descleña otras actitudes filosóficas, ni se les reemplaza por las pautas existencialistas, sino más bien, se resalta la originalidad del existencialismo frente a problemas aún caóticos.

En síntesis el existencialismo estético, proporciona estimables observaciones para ahondar en la esercia de lo estético, ellas son: 19 Poner de manifiesto el sentido de la experiencia estética, señalando el punto de partida para futuros estudios. $2^{\circ}$ Proponer estratos en el vivir estético, variedad que ño desvirtúa su Inaturaleza. 3" Descubrir la unidad estético-extraestética, sin confundir ambos aspectos. 49 Encontrar on la creación artística, el momento propicio pard inquirir por la estructura estética y 5 ? Superar las hasta ahora insalvables vallas subjetivoobjetivas en la apreciación del hecho estético. 